of the government's ambitious agenda for modernisation are likely. ${ }^{3}$

Contributors: HTOD and TGR designed the study; C-LH collected the data and did the analysis; HTOD led on writing the paper, with substantial contributions from TGR and C-LH. HTOD acts as guarantor.

Funding: Nuffield Trust, London, and the Commonwealth Fund, New York. The guarantor accepts full responsibility for the conduct of the study, had access to the data, and controlled the decision to publish.

Competing interests: None declared.

1 Edwards N, Marshall M. Doctors and managers. BMJ 2003;326:116-7.

2 Protopsaltis G, Fulop N, Edwards N, Meara R. Failure and turnaround. London: NHS Confederation, 2003.

3 McLellan A. A nasty kick in the ballots. Health Serv J 2002: 14 November, pp18-19.

(Accepted 4 March 2003)
Department of

Medicine, Division

of Infectious

Diseases, Karolinska

Institute, Karolinska

Hospital, S-171 76

Stockholm, Sweden

Anna Färnert

medical doctor

Mita M Thapar

PhD student

Anders Björkman

professor

Sándor Berezcky

PhD student

Department of

Infectious Diseases,

Sahlgrenska

University Hospital,

Östra, Gothenburg,

Sweden

Johan Lindberg

associate professor

Department of

Pharmaceutical

Biosciences,

Division of

Microbiology,

Uppsala University,

Uppsala, Sweden

Göte Swedberg

associate professor

Centro de Malária e

outras Doencas

Tropicais, Instituto

de Higiene e

Medicina Tropical,

Universidade Nova

de Lisboa, Lisboa,

Portugal

Pedro Gil

post doctoral

researcher

Department of

Clinical Chemistry,

Falun Central

Hospital, Falun and

Dalarna University

College, Borlänge,

Sweden

Yngve Berqvist

associate professor

Niklas Lindegårdh

PhD student

Correspondence to:

A Färnert

anna.farnert@

medks.ki.se

BMJ 2003;326:628-9

\title{
Evidence of Plasmodium falciparum malaria resistant to atovaquone and proguanil hydrochloride: case reports
}

Anna Färnert, Johan Lindberg, Pedro Gil, Göte Swedberg, Yngve Berqvist, Mita M Thapar, Niklas Lindegårdh, Sándor Berezcky, A Björkman

The increased spread of drug resistant malaria highlights the need for alternatives for treatment and chemoprophylaxis. The combination of atovaquone and proguanil hydrochloride (Malarone, GlaxoSmithKline, NC) has shown high efficacy against Plasmodium falciparum with only mild side effects and has been registered for use in several countries, including Denmark, Germany, Sweden, the United Kingdom, and the United States. ${ }^{1}$ Treatment failures have been attributed to suboptimal dosage, reinfections, or to a point mutation in the cytochrome $b$ gene. ${ }^{12}$ Bioavailability of atovaquone depends on the concomitant intake of a fatty diet, yet drug concentrations were not analysed in these reports. We provide evidence of resistance in two

Details of three patients treated with atovaquone and proguanil hydrochloride (Malarone; GlaxoSmithKline) for Plasmodium falciparum malaria

\begin{tabular}{|c|c|c|c|c|}
\hline \multirow[b]{2}{*}{ Patients' details } & \multirow[b]{2}{*}{ Infected erythrocytes (\%) } & \multirow[b]{2}{*}{ No of tablets } & \multicolumn{2}{|c|}{ Gene mutations* } \\
\hline & & & Cytochrome b & Dihydrofolate reductase \\
\hline \multicolumn{5}{|l|}{ Case 1 (11 kg) } \\
\hline Day of presentation & 1 & 2 & Wild type & Wild type \\
\hline \multicolumn{5}{|c|}{ Days after presentation: } \\
\hline 1 & 5 & 1 & & \\
\hline 2 & 4 & Mefloquine $\dagger$ & & \\
\hline 4 & Gametocytes only & & & \\
\hline 7 & Gametocytes only & & Wild type & Wild type \\
\hline 28 & 0 & & & \\
\hline \multicolumn{5}{|l|}{ Case $2(19 \mathrm{~kg})$} \\
\hline Day of presentation & 0.5 & 1 & Mutant type 1 & Wild type \\
\hline \multicolumn{5}{|c|}{ Days after presentation: } \\
\hline 1 & & 1 & & \\
\hline 2 & 0.2 & 1 & & \\
\hline 4 & Gametocytes only & & Negative & Negative \\
\hline 7 & Gametocytes only & & Negative & Negative \\
\hline 28 & 1.6 & Mefloquine† & Mutant type 1 & Mutant type 2 \\
\hline \multicolumn{5}{|l|}{ Case 3 (101 kg) } \\
\hline Day of presentation & Few rings & 4 & Mutant type 1 & Wild type \\
\hline \multicolumn{5}{|c|}{ Days after presentation: } \\
\hline 1 & & 4 & & \\
\hline 2 & 0 & 4 & & \\
\hline 3 & Gametocytes only & & Mutant type 1 & Negative \\
\hline 7 & Gametocytes only & & Mutant type 1 & Negative \\
\hline 28 & 0 & & Negative & Negative \\
\hline
\end{tabular}

Mutant type 1=locus 268-Ser. Mutant type 2=loci 51-Ile, 59-Arg, and 108-Asn.

*Detected by polymerase chain reaction.

tRescue treatment. patients treated with atovaquone and proguanil hydrochloride for P falciparum infection.

\section{Methods and results}

In September 2000, two boys and their mother were diagnosed as having $P$ falciparum malaria at the university hospital in Gothenburg, after returning from an eight week visit to the Ivory Coast. They had taken chloroquine weekly and proguanil daily for chemoprophylaxis against malaria. Case 1, the youngest boy (18 months), had fever, convulsions, and 1\% infected erythrocytes. He was treated with atovaquone and proguanil hydrochloride (table). His fever continued, and 
he had a few convulsions but no impaired consciousness or other signs of severe malaria. On day 2 the parasitaemia was $4 \%$. Treatment was changed to mefloquine, which was successful. His 4 year old brother, case 2 , was febrile with $0.5 \%$ infected erythrocytes. His symptoms resolved with atovaquone and proguanil hydrochloride, and the parasites were cleared after three days. On day 28 he was again febrile with $P$ falciparum parasites and was successfully treated with mefloquine. The mother (case 3), although asymptomatic, had a few $P$ falciparum rings. She was treated with atovaquone and proguanil hydrochloride, which cleared the parasites without recrudescence.

Drug concentrations were measured by high pressure liquid chromatography in repeated serum samples. The concentrations of atovaquone (7.6-13.9 $\mu \mathrm{M})$, proguanil (300-1200 $\mathrm{nM})$, and cycloguanil (125-400 nM) were all above the levels considered therapeutic in children and adults. ${ }^{3}$ Treatment failure could therefore not be attributed to poor bioavailability of the drug.

Cases 1 and 3 were infected with single clones whereas case 2 had five genetically diverse parasite populations, detected by analysis of merozoite surface proteins 1 and 2. Mutation A803G (changing tyrosine to serine in 268) in cytochrome b, related to resistance to atovaquone, was detected in cases 2 and 3 by polymerase chain reaction and restriction fragment length polymorphism of loci 133, 268, 272, 275, 280, and 284, and confirmed by sequencing (table). ${ }^{4}$ However, only wild types were found in case 1 . Analyses of loci 51, 59, 108, and 164 in the dihydrofolate reductase gene, related to resistance to proguanil and cycloguanil, revealed wild types in all samples except those from case 2 , in which triple mutation were found at recrudescence. ${ }^{5}$

\section{Comment}

Treatment of three patients with atovaquone and proguanil hydrochloride for $P$ falciparum malaria was unsuccessful in two non-immune children but successful in an adult with probable partial protective immunity. The patients had adequate blood concentrations of the drugs, indicating resistance by $P$ falciparum. Mutation in cytochrome b may have contributed to treatment failure but cannot be the only mechanism for resistance to the drug combination because it was also detected in the patient who responded well and was not detected in the patient with early treatment failure. Atovaquone and proguanil hydrochloride represents one of the main new developments in malaria chemotherapy, but because of the resistance shown at this early stage there is a need for careful surveillance of drug efficacy.

Contributors: JL treated the patients. AF coordinated the analyses and wrote the paper with the assistance of the other authors, specifically AB. NL, YB, and MT performed the pharmacological analyses. PG, GS, and SB performed the genetic analyses. AF will act as guarantor for the paper.

Funding: None.

Competing interests: JL has been reimbursed by GlaxoSmith Kline for speaking at a meeting.

1 Looareesuwan S, Chulay JD, Canfield CJ, Hutchinson DB. Malarone (atovaquone and proguanil hydrochloride): a review of its clinical development for treatment of malaria. Am J Trop Med Hyg 1999;60:533-41.

2 Fivelman QL, Butcher GA, Adagu IS, Warhurst DC, Pasvol G. Malarone treatment failure and in vitro confirmation of resistance of Plasmodium falciparum isolates from Lagos, Nigeria. Malaria J 2002;1:1.

3 Sabchareon A, Attanath P, Phanuaksook P, Chanthavanich P, Poonpanich $\mathrm{Y}$, Mookmanee D, et al. Efficacy and pharmacokinetics of atovaquone and proguanil in childen with

4 Korsinczky M, Chen N, Kotecka B, Saul A, Rieckmann K, Cheng Q. Mutations in Plasmodium falciparum cytochrome $\mathrm{b}$ that are associated with atovaquone resistance are located at a putative drug-binding site. Antimicrob Agents Chemother 2000;44:2100-8.

5 Sirawaraporn W, Sathitkul T, Sirawaraporn R, Yuthavong Y, Santi DV. Antifolate-resistant mutants of Plasmodium falciparum dihydrofolate reductase. Proc Natl Acad Sci USA 1997;94:1124-9.

(Accepted 9 January 2003)

\title{
Media criticism of doctors: review of UK junior doctors' concerns raised in surveys
}

\author{
Michael J Goldacre, Julie Evans, Trevor W Lambert
}

We conduct regular surveys of junior doctors' career intentions and views on their training and work. ${ }^{12}$ At the end of the structured questionnaire we invite respondents to add comments on any aspect of their career choice, training, or work. The great majority of the comments we receive relate to topics raised by us, although some respondents raise other topics. In the replies to questionnaires sent to doctors who qualified in 1999 and 2000, a new theme (not raised by us) emerged among the comments: critical portrayal of doctors in the news media. We report on these comments here.

\section{Method and results}

We sent questionnaires to all doctors who qualified from any UK medical school in 1993, 1996, 1999, and 2000; we did this towards the end of their preregistration year. In all, 5547 (74\%) of the 7466 qualifiers of 1993 and 1996 replied, as did 5702 (67\%) of the 8494 qualifiers of
1999 and 2000. Forty per cent (2194) of the respondents of 1993 and 1996 added written comments on their questionnaires, as did 39\% (2217) of those of 1999 and 2000. Comments were keyed and imported into software designed for coding and searching text. ${ }^{3}$ After reading the doctors' comments, we decided to search systematically for all comments that included the text strings "media," "press," "news," "newspapers," "doctor bashing," and "doctor-bashing." We read all comments extracted by this search and eliminated any that used the word(s) in a different context from concerns about the portrayal of doctors in the news media.

This yielded comments from three respondents from the combined 1993 and 1996 cohorts and 63 from the combined 1999 and 2000 cohorts. The box shows some of these comments (verbatim)-chosen to represent the main issues raised and to illustrate the wide geographical spread of those who raised them. They tended to make their comments about the media
UK Medical Careers Research Group, Unit of Health-Care Epidemiology, Department of Public Health, University of Oxford, Institute of Health Sciences, Oxford OX3 7LF Michael J Goldacre director

Julie Evans social scientist Trevor W Lambert statistician

Correspondence to: MJ Goldacre michael.goldacre@ dphpc.ox.ac.uk

BMJ 2003;326:629-30 